\title{
Laughter catches attention!
}

Citation for published version (APA):

Pinheiro, A. P., Barros, C., Dias, M., \& Kotz, S. A. (2017). Laughter catches attention! Biological

Psychology, 130, 11-21. https://doi.org/10.1016/j.biopsycho.2017.09.012

Document status and date:

Published: 01/12/2017

DOI:

10.1016/j.biopsycho.2017.09.012

Document Version:

Publisher's PDF, also known as Version of record

\section{Document license:}

Taverne

\section{Please check the document version of this publication:}

- A submitted manuscript is the version of the article upon submission and before peer-review. There can be important differences between the submitted version and the official published version of record.

People interested in the research are advised to contact the author for the final version of the publication, or visit the DOI to the publisher's website.

- The final author version and the galley proof are versions of the publication after peer review.

- The final published version features the final layout of the paper including the volume, issue and page numbers.

Link to publication

\footnotetext{
General rights rights.

- You may freely distribute the URL identifying the publication in the public portal. please follow below link for the End User Agreement:

www.umlib.nl/taverne-license

Take down policy

If you believe that this document breaches copyright please contact us at:

repository@maastrichtuniversity.nl

providing details and we will investigate your claim.
}

Copyright and moral rights for the publications made accessible in the public portal are retained by the authors and/or other copyright owners and it is a condition of accessing publications that users recognise and abide by the legal requirements associated with these

- Users may download and print one copy of any publication from the public portal for the purpose of private study or research.

- You may not further distribute the material or use it for any profit-making activity or commercial gain

If the publication is distributed under the terms of Article $25 \mathrm{fa}$ of the Dutch Copyright Act, indicated by the "Taverne" license above, 
Research paper

\title{
Laughter catches attention!
}

\author{
Ana P. Pinheiro ${ }^{\mathrm{a}, \mathrm{b}, *}$, Carla Barros ${ }^{\mathrm{b}}$, Marcelo Dias ${ }^{\mathrm{b}}$, Sonja A. Kotz ${ }^{\mathrm{c}, \mathrm{d}}$ \\ a Universidade de Lisboa, Faculdade de Psicologia, CICPSI, Lisboa, Portugal \\ b Neuropsychophysiology Laboratory, School of Psychology, University of Minho, Braga, Portugal \\ ${ }^{c}$ Department of Neuropsychology, Max Planck Institute for Human Cognitive and Brain Sciences, Leipzig, Germany \\ ${ }^{\mathrm{d}}$ Faculty of Psychology and Neuroscience, Department of Neuropsychology \& Psychopharmacology, Maastricht University, The Netherlands
}

\section{A R T I C L E I N F O}

\section{Keywords:}

Voice

Emotion

Attention

EEG

P3

Alpha power

\begin{abstract}
A B S T R A C T
In social interactions, emotionally salient and sudden changes in vocal expressions attract attention. However, only a few studies examined how emotion and attention interact in voice processing. We investigated neutral, happy (laughs) and angry (growls) vocalizations in a modified oddball task.

Participants silently counted the targets in each block and rated the valence and arousal of the vocalizations. A combined event-related potential and time-frequency analysis focused on the P3 and pre-stimulus alpha power to capture attention effects in response to unexpected events.

Whereas an early differentiation between emotionally salient and neutral vocalizations was reflected in the P3a response, the P3b was selectively enhanced for happy voices. The P3b modulation was predicted by prestimulus frontal alpha desynchronization, and by the perceived pleasantness of the targets.

These findings indicate that vocal emotions may be differently processed based on task relevance and valence. Increased anticipation and attention to positive vocal cues (laughter) may reflect their high social relevance.
\end{abstract}

\section{Introduction}

In a constantly changing world we need to filter out information that is relevant to our needs and goals and to quickly distinguish salient from non-salient cues as our processing capacities are limited. For example, in social interactions cues that are deemed emotionally relevant such as a change of voice from neutral to angry may selectively capture attention. This ensures that processing resources are oriented towards salient events.

Compared to other non-verbal emotional cues, the voice is particularly effective in communicating emotions as it can carry information over large distances and independent of sight (e.g., Hawk, Van Kleef, Fischer, \& van Der Schalk, 2009). There is strong evidence suggesting that the perception of vocal emotional expressions engages a multistage process (Bestelmeyer, Maurage, Rouger, Latinus, \& Belin, 2014; Frühholz, Ceravolo, \& Grandjean, 2012; Paulmann \& Kotz, 2008a, 2008b; Pinheiro et al., 2013; Wildgruber, Ackermann, Kreifelts, \& Ethofer, 2006). These stages involve: 1) the sensory processing; 2) the detection of the emotional salience; and 3) the cognitive evaluation of the emotional significance of the voice (reviewed in Kotz \& Paulmann, 2011; Schirmer \& Kotz, 2006).

While there is ample evidence on attentional effects in emotional face and picture processing (e.g., Blair, Morris, Frith, Perrett, \& Dolan,
1999; Eimer \& Holmes, 2007; Keil et al., 2002; Keil, Moratti, Sabatinelli, Bradley, \& Lang, 2005; Kilts, Egan, Gideon, Ely, \& Hoffman, 2003; Lane, Chua, \& Dolan, 1999), fewer studies have examined the interaction of attention and emotion in voice perception (e.g., Grandjean et al., 2005; Sander et al., 2005). Functional magnetic resonance imaging (fMRI) studies suggest that the processing of vocal emotions is intricately associated with attention (e.g., Grandjean et al., 2005; Sander et al., 2005). Compared to neutral vocal cues, emotional vocalizations elicit increased brain activation in voice-sensitive regions (Belin, Zatorre, Lafaille, Ahad, \& Pike, 2000) and in the amygdala (e.g., Grandjean et al., 2005; Sander \& Scheich, 2001), which may lead to the prioritized processing of these acoustic events (e.g., Brosch, Grandjean, Sander, \& Scherer, 2009). However, vocal emotions are processed differently depending on whether they are (attention towards emotional cues - e.g., discrimination of the emotional tone of a voice) or not (attention away from emotional cues - e.g., gender discrimination) in the focus of attention (Frühholz \& Grandjean, 2013; Sander et al., 2005). For example, amygdala activation was observed only when attention was directed towards vocal expressions (Frühholz et al., 2012). Further, the activation of the orbitofrontal cortex and cuneus was enhanced when vocal emotions were attended rather than ignored (Sander et al., 2005). These findings suggest that attention changes the processing of vocal emotions, acting as a top-down factor leading to the

\footnotetext{
* Corresponding author at: Universidade de Lisboa, Faculdade de Psicologia, CICPSI, Alameda da Universidade, 1649-013 Lisboa, Portugal.

E-mail address: appinheiro@psicologia.ulisboa.pt (A.P. Pinheiro).
} 
prioritization of certain stimulus features (Frühholz \& Grandjean, 2013). However, emotional effects do not depend on selective attention to the voice: the brain can still detect emotional salience from voices that are not in the focus of attention (Grandjean et al., 2005).

Nonetheless, due to the low temporal resolution of fMRI, these studies cannot specify how attention affects different stages of vocal emotional processing. The temporal resolution of the electroencephalogram (EEG) is especially suitable to tackle this question as it may provide critical hints about the speed at which vocal emotional information is decoded and at the processing stages involved (e.g., Kotz \& Paulmann, 2011). The existing event-related potential (ERP) studies have revealed effects of salience on selective attention processes around 300 ms post-stimulus onset reflected in the P3 component (e.g., Campanella et al., 2010; Delplanque, Silvert, Hot, Rigoulot, \& Sequeira, 2006; Pinheiro, Barros, \& Pedrosa, 2016).

\subsection{Probing effects of emotion on attention in voice processing with ERPs}

In the classical oddball paradigm, a low-probability stimulus (target) is embedded in a series of frequent or non-relevant (non-target) stimuli and needs to be detected. The classical P3 response to target stimuli is considered to reflect the top-down allocation of attentional resources (e.g., Polich, 2007) and has also been linked to the updating of a model of the environment in memory (e.g., Donchin, 1981; Donchin \& Coles, 1988; Kotz, Stockert, \& Schwartze, 2014).

Rather than representing a single process, the P3 is composed of dissociable and independent components. The fronto-central P3a is elicited by rare or novel task-irrelevant stimuli (e.g., Courchesne, Hillyard, \& Galambos, 1975; Squires, Squires, \& Hillyard, 1975) and reflects stimulus-driven attentional orienting. The centro-parietal P3b has a later latency, is elicited by infrequent task-relevant stimuli, and reflects top-down processes of attention leading to an update of a mental model of the environment as a function of stimulus salience (e.g., Polich, 2007; Sutton, Braren, Zubin, \& John, 1965). Several studies have shown that the infrequent target stimuli may elicit both a P3a and a P3b component (Delplanque et al., 2006; Goldstein, Spencer, \& Donchin, 2002; Spencer, Dien, \& Donchin, 1999, 2001). This suggests that each potential is an index of attention allocation at different levels (Polich, 2007). As the P3a and P3b components are evoked very closely in time, spatiotemporal decomposition methods (e.g., Principal Component Analysis) represent a more adequate approach to separate superimposed ERP components (e.g., Pinheiro et al., 2016; Spencer et al., 1999, 2001).

Few studies have tested the P3 complex to examine emotional processes and most have used visual stimuli such as pictures. These studies have consistently shown the increased attention-grabbing properties of emotional compared to neutral cues, reflected in an enhanced P3b response (e.g., Briggs \& Martin, 2009; Schupp, Junghöfer, Weike, \& Hamm, 2003). Some have reported increased P3a or P3b responses to negative compared to positive stimuli such as pictures (e.g., P3a - Delplanque et al., 2006; P3b - Ito, Larsen, Smith, \& Cacioppo, 1998) or words (e.g., P3b - Bernat, Bunce, \& Shevrin, 2001). The observed negativity bias may be explained by the critical role played by the accurate recognition of negative emotions (e.g., fear or anger) in survival (e.g., Adolphs, 2002). Other studies revealed specific differences in the P3a and P3b in response to pictures as a function of their valence (i.e., its perceived pleasantness $v s$. unpleasantness) $v s$. arousal (i.e., the degree of activation elicited by the stimulus). Delplanque et al. (2006) observed valence effects in the P3a (increased P3a amplitude for negative compared to both neutral and positive pictures), and arousal effects in the P3b (increased P3b amplitude for both positive and negative compared to neutral pictures).

Evidence from auditory emotion studies is less consistent. Two studies found modulatory effects of salience on attention processes reflected in the P3b. Goydke, Altenmüller, Möller, and Münte (2004) presented single musical tones played by a violin in a certain pitch, expressing happy or sad sounds in an oddball task, and found that the P3b was elicited earlier for happy than for sad target sounds. Campanella et al. (2010) reported earlier P3b latencies for happy than for sad prosodic speech targets (i.e. the word "paper" spoken in a happy or sad tone of voice). Two studies reported salience effects in the P3a. Thierry and Roberts (2007) found that the P3a response is increased for novel unpleasant sounds, suggesting that negative stimuli elicit spontaneous attentional orienting when compared to neutral stimuli, but no comparison was made with positive vocal stimuli. Pinheiro et al. (2016) probed how the salience of task-irrelevant and unexpected vocalizations modulates attention orienting, and found an increased P3a response for both negative (growls) and positive (laughs) vocalizations compared to neutral vocalizations. These findings corroborate the idea that emotionally relevant cues are prioritized and that stimulus valence influences how attentional resources are mobilized (e.g., Brosch, Grandjean, Sander, \& Scherer, 2008; Sander et al., 2005). Contrary to studies on visual emotional processing, none of these auditory studies reported a negativity bias. As much of the past emotion research has focused on threat-related cues, the effects of similarly arousing positive vocalizations have yet to be understood.

The prevalent view that negative stimuli are more salient has been questioned by recent studies showing that positive stimuli elicit similar effects to negative ones when carefully controlled for arousal (e.g., Brosch, Sander, Pourtois, \& Scherer, 2008). Indeed, affiliative vocal signals such as happy voices play a fundamental role in social bonding and, hence, may lead to preferential processing. In support of this hypothesis, previous fMRI studies have demonstrated greater activation for happy than angry voices, when attention was directed to the voice, in the anterior and posterior middle temporal gyrus, the inferior frontal gyrus of the right hemisphere, the amygdala and the insula (Johnstone, van Reekum, Oakes, \& Davidson, 2006). The apparent discrepancy between visual and auditory emotional studies may be explained by methodological differences (e.g., modality of stimulus presentation; ecological validity of the material; absence of a positive condition in some of the designs). Clarifying how valence modulates attention processes in voice perception is, therefore, essential.

\subsection{Probing effects of vocal emotion on attention with neural oscillations}

Next to ERPs, the analysis of the EEG time-frequency domain may elucidate how negative and positive vocalizations differently modulate attentional resources. As the information contained in vocalizations is unfolding over time, and there is no clear emotion recognition point, the information provided by non-phase locked neural oscillatory changes in EEG power is of great interest (e.g., Jessen \& Kotz, 2011). Contrary to evoked oscillations, induced oscillatory activity is not characterized by a constant time and phase relationship with the eliciting stimulus (e.g., Deiber et al., 2007).

Oscillatory activity in the alpha band $(8-12 \mathrm{~Hz})$ plays a pivotal role in attentional processes (reviewed by Klimesch, 2012) and may govern the relationship of the P3 to attention (Polich, 1997). Even though only a small number of studies on emotional processing analyzed neural oscillations, in these studies alpha oscillations were sensitive to the emotional quality of a stimulus. Specifically, decreased alpha power ${ }^{1}$ was reported for emotional relative to neutral pictures (e.g., Balconi, Falbo, \& Brambilla, 2009) or for emotional relative to neutral audiovisual and visual clips (Jessen \& Kotz, 2011). These effects were interpreted as reflecting an increased capture of attention as a result of enhanced stimulus saliency (Jessen \& Kotz, 2011).

Next to the functional relevance of alpha oscillations in attentional processes, it is apparent that alpha oscillations also play a role in the anticipation of upcoming events. A reduction in pre-stimulus alpha

\footnotetext{
${ }^{1}$ The transient decrease of the power of brain oscillations has been termed "desynchronization" (Neuper \& Pfurtscheller, 2001)
} 
power was observed in response to an expected target in a variant of the Posner paradigm, in which participants were provided with predictive information (e.g., the location of a target or a distractor) or not (Noonan et al., 2016). Moreover, anticipatory attention (i.e., attention directed towards an upcoming stimulus to facilitate its processing) was reflected in pre-stimulus alpha power attenuation in the sensory cortex of the modality of the anticipated stimulus (Bastiaansen \& Brunia, 2001; Rohenkohl \& Nobre,2011).

Despite the contributions of the studies reviewed above, two fundamental aspects remain unclear: whether and how anticipatory processes in voice perception are modulated by stimulus valence, and how these processes affect attention to task-relevant vocal cues.

\subsection{The current study and hypotheses}

In order to investigate how vocal emotions differentially affect attention processes as a function of valence, we applied a modified oddball paradigm with neutral, happy, and angry vocalizations. Studying both attended, task-relevant (target), and task-irrelevant (standard) vocal emotional stimulus processing, it is possible to scrutinize the salience of emotional stimuli by altering the attentional focus. Different types of vocalizations were presented both as standards and targets in separate experimental blocks. This was done to reduce the effects of acoustic differences between the neutral and emotional stimuli as each vocalization served as its own acoustic control. Anger and happiness were selected because they have similar acoustic profiles such as high intensity and variable F0 (e.g., Banse \& Scherer, 1996), and they represent emotional categories that regularly occur in social contexts. Both voltage and time-frequency domain analyses were used to enable inferences about temporal dynamics in the interaction of emotion and attention. The focus was on the P3 complex and non-phase locked alpha power. A principal component analysis was used to dissociate early (P3a) and late (P3b) attention effects.

We expected both the $\mathrm{P} 3 \mathrm{a}$ and the $\mathrm{P} 3 \mathrm{~b}$ to be sensitive to the emotional significance of the voice (Campanella et al., 2010; Goydke et al., 2004; Pinheiro et al., 2016; Thierry \& Roberts, 2007). Specifically, we hypothesized that attention orienting (P3a) would be enhanced for both laughs and growls compared to neutral vocalizations, whereas no differentiation between positive and negative vocal sounds would occur at this stage (Pinheiro et al., 2016). We expected valence-related differences in the P3b response, reflecting differences in the top-down allocation of attentional resources for subsequent context updating, as a function of the perceived pleasantness $v$ s. unpleasantness of the stimulus (Campanella et al., 2010; Goydke et al., 2004). In particular, if the negativity bias reported in studies of visual emotional perception (e.g., Ito et al., 1998) is also observed during vocal emotional processing, we predicted that the P3b would be enhanced for growls. On the other hand, if the positive motivational system responds more to emotional vocal expressions (positivity offset account - Ito \& Cacioppo, 2005), consistent with the observations of previous fMRI studies (e.g., Johnstone et al., 2006), the P3b would be increased for laughs relative to growls.

Furthermore, we expected stronger pre-stimulus alpha desynchronization in response to emotional compared to neutral vocalizations, reflecting enhanced anticipation of salient sounds (Bastiaansen \& Brunia, 2001)

\section{Method}

\subsection{Participants}

Nineteen college students (10 female) participated in the study (mean age $=23.43, S D=3.60$ years). The inclusion criteria were: (a) European Portuguese as their native language; (b) being right-handed (Oldfield, 1971); (c) no history of neurological illness; (d) no history of DSM-IV diagnosis of drug or alcohol abuse (American Psychiatric
Association, 2000); (e) no present medication for medical disorders that could affect the electroencephalogram (EEG) morphology; (f) normal or corrected-to-normal hearing and vision; ( $g$ ) no history of psychiatric disorder in oneself or in first-degree relatives. Before the EEG experiment, a brief clinical assessment aimed to rule out the presence of psychopathological symptoms (Brief Symptom Inventory - Canavarro, 1999; $M=1.25, S D=0.18$ ). None of the participants had total scores that indicated the presence of clinical symptoms.

Participants were given course credit for their participation. The study was conducted in accordance with the Declaration of Helsinki and approved by the local ethics committee (University of Minho). All participants provided written informed consent for the experimental protocol.

\subsection{Stimuli}

Experimental stimuli were three female vocalizations selected from the Montréal Affective Voices set (MAV - Belin, FillionBilodeau, \& Gosselin, 2008), with positive (laughs), negative (growls), and neutral (the vowel $a h-/ \mathrm{a} /$ with neutral intonation) valence. The duration of vocalizations was shortened so that stimuli lasted only $700 \mathrm{~ms}$ but their emotional content was preserved. ${ }^{2}$ Stimuli were normalized in mean intensity $(70 \mathrm{~dB})$ using a Praat script (Boersma, \& Weenink, 2013). The fundamental frequency was $190.57 \mathrm{~Hz}$ for the neutral vocalization, $341.27 \mathrm{~Hz}$ for the happy vocalization, and $397.52 \mathrm{~Hz}$ for the angry vocalization. Stimuli were selected based on affective ratings (valence, arousal, dominance) of both original and shortened MAV stimuli (90 nonverbal affect bursts), using the Self-Assessment Manikin (Bradley \& Lang, 1994), obtained in a previous study with 60 college students (30 female; mean age $=22.05$, $S D=3.39$ years). None of these participants took part in the EEG experiment. The validation procedure took place in a quiet room, in groups of 8 students. First, instructions were projected on a white screen, and followed by a verbal explanation of the procedure. Each trial had the following structure: a number corresponding to a sound appeared on the screen for $3 \mathrm{~s}$ after which the sound was played via loudspeakers. At the end of the sound, participants were prompted to register their response on the provided response sheet. A 9-point-SAM scale (Bradley \& Lang, 1994) was used to assess the valence (measuring the unpleasantness or pleasantness of the stimulus, from $1=$ completely unpleasant to $9=$ completely pleasant), arousal (measuring the level of activation elicited by a given stimulus, from $1=$ not aroused to $9=$ completely aroused), and dominance (reflecting the sense of control over a given situation or stimulus, from $1=$ feeling completely dominated to $9=$ feeling completely in control) of each vocal stimulus. The next trial started after $17 \mathrm{~s}$. Results are presented in Table 1 . The vocalizations selected for the study elicited the most consistent affective ratings in the validation task.

\subsection{Procedure}

The experiment was conducted in a dimly lit, sound-attenuated, and electrically shielded room. Participants were seated in a comfortable chair at $100 \mathrm{~cm}$ distance from a liquid-crystal display (LCD) screen. Presentation software, version 16.3 (Neurobehavioral Systems, Inc., Albany NY, USA) was used to control the presentation and timing of the stimuli.

Vocalizations were presented in 4 blocks separated by brief rest periods, either as standard or target (deviant) sounds: block 1-neutral standards and happy targets; block 2-happy standards and neutral

\footnotetext{
${ }^{2}$ In order to reduce duration, Praat software (Boersma \& Weenink, 2013) was used: first the most steady-state portion of vocal sounds was selected and individual waves were manually cut at zero crossings (where the wave crosses zero amplitude) to avoid clicks; then, depending on the recording, pauses were reduced.
} 
Table 1

Affective Normative Ratings of the Experimental Stimuli.

\begin{tabular}{|c|c|c|c|c|}
\hline \multirow{2}{*}{$\begin{array}{l}\text { Type of } \\
\text { Vocalization }\end{array}$} & \multicolumn{4}{|c|}{ Affective Dimension } \\
\hline & Valence & Comparisons & Arousal & Comparisons \\
\hline Neutral & $4.67(0.90)$ & $\mathrm{NEU}>\mathrm{ANG}^{* * *}$ & $3.32(2.29)$ & HAP $>\mathrm{NEU}^{* * *}$ \\
\hline $\begin{array}{l}\text { Happy } \\
\text { (Laughs) }\end{array}$ & $7.62(1.25)$ & $\begin{array}{l}\text { HAP }>\mathrm{NEU}^{* * *} \\
\mathrm{HAP}>\mathrm{ANG}^{* * *}\end{array}$ & $5.33(2.24)$ & ANG $>\mathrm{NEU}^{* * *}$ \\
\hline Angry (Growls) & $3.40(1.66)$ & & $5.72(2.18)$ & \\
\hline
\end{tabular}

Note: $\quad$ NEU $=$ neutral; $\quad$ HAP $=$ happy $\quad$ ANG $=$ angry; $M(S D)$ values are shown. Statistically significant differences are marked by asterisks:

$* * * p<0.001$ (based on paired sample $t$-tests).

targets; block 3-neutral standards and angry targets; block 4-angry standards and neutral targets. Each experimental block included 210 standard $(P=0.084)$ and 40 target $(P=0.016)$ vocal sounds. Stimuli within each block were presented in a pseudo-randomized order, with a minimum of six standards occurring between each target. The order of blocks was counterbalanced across participants. The structure of an experimental trial is illustrated in Fig. 1.

Vocalizations were delivered binaurally through Sennheiser CX 300II headphones at an intensity of $70 \mathrm{~dB}$ SPL. Before the experimental session, a training session using different stimuli took place so that participants could familiarize themselves with the instructions and the task. Participants were instructed to silently count the number of target vocalizations in each block. Counting accuracy was recorded and provided a measure of task performance. At the end of the EEG session, participants were instructed to rate the valence and arousal of the vocalizations using the 9-point SAM scale (Bradley \& Lang, 1994).

\subsection{EEG data acquisition and analyses}

\subsubsection{EEG data acquisition}

EEG data were recorded using a 64-channel Active Two Biosemi system (Biosemi, Amsterdam, The Netherlands) in a continuous mode at a digitization rate of $512 \mathrm{~Hz}$, and stored on disk for later analysis. Eye blinks and movements were monitored through electrodes placed on both temples (horizontal electrooculogram) and another one below the left eye (vertical electrooculogram). During data acquisition, the activity in all channels was referred to the system's internal loop (CMS/ DRL sensors).

EEG data were analyzed using EEGLAB 13.1.1b software (Delorme \& Makeig, 2004) and in-house developed Matlab functions (Mathworks Inc.). Data were referenced offline to the average of the left and right mastoids and high-pass filtered with a $0.1 \mathrm{~Hz}$ filter. Individual epochs were created for each stimulus type (neutral, happy, angry), with a $-700 \mathrm{~ms}$ pre-stimulus baseline and $1300 \mathrm{~ms}$ post-stimulus epoch. The vertical electrooculogram (EOG) was derived by subtracting the activity measured at an electrode positioned below the left eye from an electrode positioned above it. The horizontal EOG was derived by subtracting the activity measured between electrodes placed at the outer canthi of the eyes. An independent component analysis was used to remove ocular and muscle artifacts. Independent components representing artifacts were identified on the basis of their characteristic topography, temporal, and spectral features (e.g., Hipp \& Siegel, 2013; Keren, Yuval-Greenberg, \& Deouell, 2010). After artifact rejection, at least $83 \%$ of trials per condition per participant were entered in the statistical analyses. The number of individual trials did not differ between conditions $(p>0.05)$. In order to have the same number of averaged standard and target stimuli, only the non-rejected standard stimuli immediately preceding the targets were included in the averages.

\subsubsection{ERP analyses}

For ERP analyses, the EEG signal was corrected using the -200 to $0 \mathrm{~ms}$ pre-stimulus interval as a baseline. Individual ERP averages were derived for each stimulus condition (see Fig. 2). A spatio-temporal Principal Component Analysis (PCA) was used to most accurately capture the spatial topography of evoked responses over time and to functionally separate distinct events that occur simultaneously in time, following the procedures described in Spencer et al. (1999, 2001). The data set used in the PCA consisted of the ERP averages at each electrode site in all stimulus conditions per participant, using the $800 \mathrm{~ms}$ portion of the epoch (409 time-points). The data matrix input to the spatial PCA consisted of 61 (oculars excluded) electrode sites x 46626 observations (409 time-points x 6 stimulus conditions x 19 participants). Based on the scree test (Cattell, 1966), 5 spatial factors (SFs) explained most of the variance in the data set and were extracted for rotation with the Varimax procedure. In this first step, SF loadings were computed (variables $=$ electrode sites; observations $=$ time-points, experimental conditions, and participants). The covariance between electrode sites was analyzed across the time-points of the averages for each stimulus condition and participant. 'Virtual electrodes' represent the SFs that inform about the spatial variance in the data, reflecting scalp distributions and not typical ERP components and, as such, are not comparable to voltage maps. SF scores may be plotted as time series for each condition and participant ('virtual ERPs'). Topographical maps of the voltage data and SF loadings were plotted using spherical line interpolation. A temporal PCA was then run on the SF scores, using Varimax rotation (variables $=\mathrm{SF}$ scores or 'virtual ERPs' associated with the time-points; observations = 'virtual electrodes', conditions,

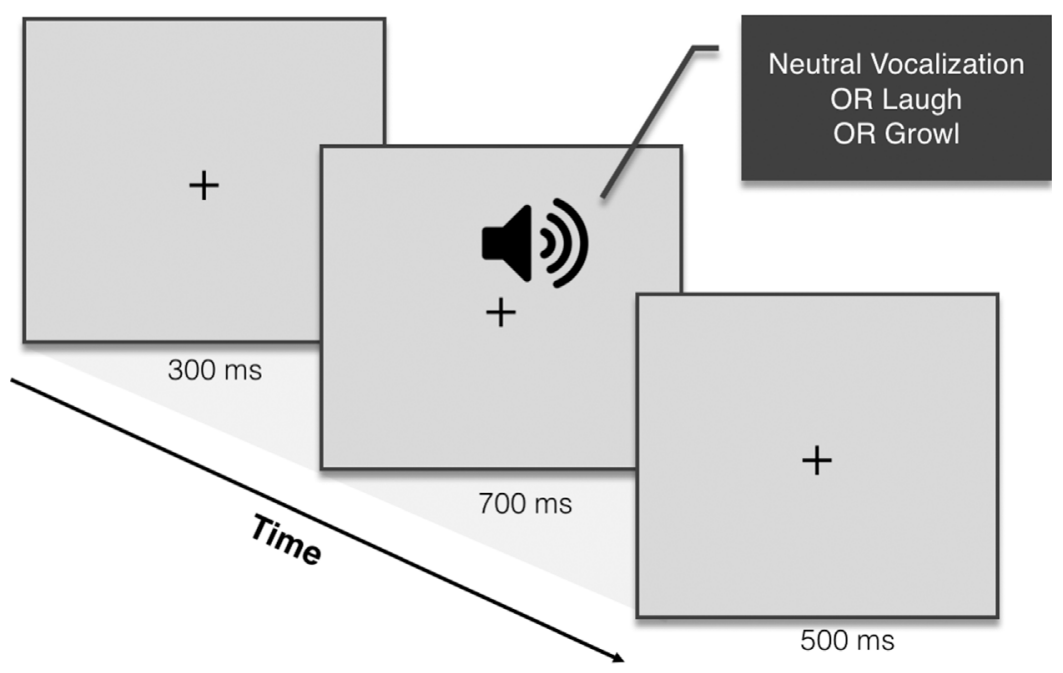

Fig. 1. Schematic illustration of an experimental trial. 

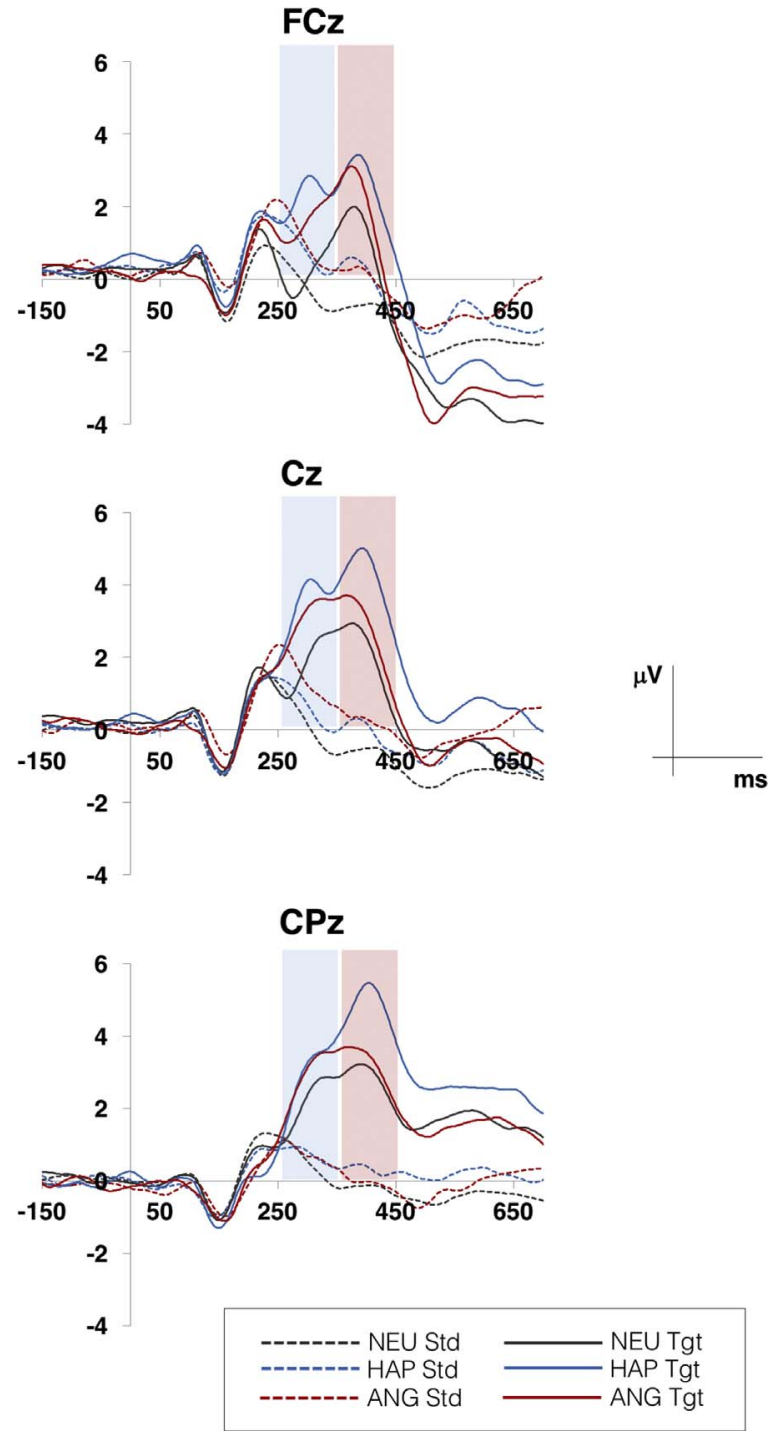

Fig. 2. Grand average waveforms for neutral, happy (laughs), and angry (growls) vocalizations presented as task-irrelevant (standard) and task-relevant (deviant) sounds at midline electrode sites $(\mathrm{FCz}, \mathrm{Cz}, \mathrm{CPz})$.

Note: Std $=$ standard; Tgt $=$ target; NEU $=$ neutral; HAP $=$ happy; ANG $=$ angry.

The colored boxes illustrate the time windows showing the P3a (blue) and P3b (red) effects: the P3a was increased for emotional (happy and angry) compared to neutral vocalizations; the P3b was increased for happy relative to angry and neutral vocalizations.

and participants). Then, the covariance between time-points for all the virtual electrodes, participants, and experimental conditions was analyzed. The resulting temporal factor (TF) scores for each SF were used to measure the activity in the ERP component with the temporal morphology and scalp distribution of interest. Factor scores represent a unitless dimension (see Spencer et al., 1999, 2001).

\subsubsection{EEG Time-frequency domain analyses}

The ERP analysis do not allow capturing a critical element of the neural response, i.e. the time-locked but not phase-locked (or induced) oscillatory activity. Evoked and induced responses differ in the degree to which the underlying neural activity is phase-locked to the stimulus over trials, reflecting different neurocognitive mechanisms (Cohen \& Donner, 2013; David, Kilner, \& Friston, 2006; Klimesch, Doppelmayr, Russegger, Pachinger, \& Schwaiger, 1998; Klimesch, Russegger, Doppelmayr, \& Pachinger, 1998). For time-frequency analyses, the EEG data were re-referenced offline to the average reference. Time frequency decomposition was performed using a Complex
Morlet's wavelet transform, applied in $0.25 \mathrm{~Hz}$ steps from 4 to $60 \mathrm{~Hz}$ at each time point to yield time-frequency (TF) maps of induced power. The wavelet transformation of the EEG signal allows the analysis of activity that appears with a latency jitter from trial to trial, which tends to disappear in the averaged evoked potentials. The constant ratio of central frequency ( $c=f 0 / \sigma f$ ) was 7 and the multiplication factor $(m)$ was 4 (Roach \& Mathalon, 2008). The bandwidth parameter $\left(F_{B}\right)$ was defined as $2\left(\frac{n c}{m \cdot f_{0}}\right)^{2}$, where $n c$ is the number of cycles (considered $n c=4.46)$ and $f o$ the central frequency of the wavelet. A normalization factor was applied: $A=\frac{1}{\sqrt[2]{\pi F_{B}}}$. Baseline activity $(-700$ to $-300 \mathrm{~ms}$ ) was subtracted from each TF map.

The analysis of the non-phase-locked activity was performed based on time-frequency magnitude values. 'Pure' induced power was isolated by removing evoked (phase locked) power from the single-trial based total power estimate to examine modulations of alpha power that occur independently from evoked responses (ERPs are non-oscillatory responses). The induced power was determined by the difference between the total and the evoked (phase-locked) power (e.g., David et al., 2006; Roach \& Mathalon, 2008). The calculation of both measures was conducted with basis on the following equations:

$P O W_{\text {total }}(t, f)=\frac{1}{N} \sum_{n=1}^{N}\left|w(t, f)^{*} s_{n}(t)\right|^{2}$

The Eq. (1) corresponds to total power, where $N$ is the number of trials, $w(t, f)$ is the Complex Morlet's Wavelet at timepoint $t$ and frequency $f$, and $s_{n}(t)$ is the response signal of trial $n$.

$\operatorname{POW}_{\text {evoked }}(t, f)=\left|w(t, f){ }^{*} s_{E}(t)\right|^{2}$

The Eq. (2) allows to determine the phase-locked power, where $w(t, f)$ is the Complex Morlet's Wavelet and $s_{E}(t)$ is the evoked response signal (averaged across trials). In the current study, we focused exclusively on the changes in pre-stimulus activity as a function of probability and valence. For each trial, the mean induced power in the classical alpha band (as commonly defined in the literature $-8-12 \mathrm{~Hz}$ ) was calculated in a pre-stimulus interval $(-250$ to $0 \mathrm{~ms})$. $^{3}$

The IBM SPSS Statistics 22 software package (SPSS, Corp., USA) was used for statistical analyses. Analyses of variance were corrected for non-sphericity using the Greenhouse-Geisser method (the original $d f$ are reported). All significance levels are two-tailed with the preset significance level of $p<0.05$.

\section{Results}

\subsection{Behavioral results}

\subsubsection{Accuracy in counting the number of targets}

The number of target vocalizations counted in each condition was very close to the correct number (neutral: $99.22 \pm 2.06 \%$; happy: $98.95 \pm 1.73 \%$; angry: $98.83 \pm 3.68 \%$ ) confirming that participants were focusing their attention on the target stimuli during the EEG recording. No statistical differences between conditions were found $(p>0.05)$.

\subsubsection{Affective ratings}

Paired samples $t$-tests were computed to test for differences between vocalization ratings of valence and arousal. The $t$-tests revealed significant differences between vocalizations in the two affective dimensions (Table 2). Laughs were rated as more pleasant than both growls $(t$ $(18)=9.123, p<0.001)$ and neutral vocalizations $(t(18)=-8.301$, $p<0.001$ ), whereas growls were rated as less pleasant than neutral

\footnotetext{
${ }^{3}$ Based on Roach and Mathalon (2008) and others (e.g., Tallon-Baudry \& Bertrand, 1999), we isolated 'pure' induced power by removing evoked power from the single-trial based total power estimate. However, there is no general agreement on how the subtraction should be performed (Roach \& Mathalon, 2008).
} 
Table 2

Affective Ratings of the Experimental Stimuli by the Participants.

\begin{tabular}{|c|c|c|c|c|}
\hline \multirow{2}{*}{$\begin{array}{l}\text { Type of } \\
\text { Vocalization }\end{array}$} & \multicolumn{4}{|c|}{ Affective Dimension } \\
\hline & Valence & Comparisons & Arousal & Comparisons \\
\hline Neutral & $4.70(0.78)$ & $\mathrm{NEU}>\mathrm{ANG}^{* * *}$ & 3.09 (1.35) & $\mathrm{HAP}>\mathrm{NEU}^{* * *}$ \\
\hline $\begin{array}{l}\text { Happy } \\
\text { (Laughs) }\end{array}$ & $7.96(0.98)$ & $\begin{array}{l}\mathrm{HAP}>\mathrm{NEU}^{* * *} \\
\mathrm{HAP}>\mathrm{ANG}^{* * *}\end{array}$ & $6.22(1.83)$ & ANG $>\mathrm{NEU}^{* * *}$ \\
\hline Angry (Growls) & $2.52(1.70)$ & & $6.83(1.40)$ & \\
\hline
\end{tabular}

Note: $\quad$ NEU $=$ neutral; $\quad \mathrm{HAP}=$ happy $\quad \mathrm{ANG}=$ angry; $M(S D)$ values are shown . Statistically significant differences are marked by asterisks:

$* * * p<0.001$ (based on paired sample $t$-tests)

vocalizations $(t(18)=5.047, \quad p<.001)$. Both growls $(t(18)$ $=-8.791, p<0.001)$ and laughs $(t(18)=-4.911, p<0.001)$ were rated as more arousing than the neutral vocalizations, but arousal ratings did not differ between growls and laughs $(p>0.05)$.

\subsection{EEG results}

\subsection{1. $P 3$}

Fig. 2 shows grand average waveforms for neutral vocalizations, laughs and growls presented as standard or target stimuli.

The spatial PCA revealed five SFs (see Supplementary Fig. 1): SF1 has a centro-parietal distribution and accounted for $18.23 \%$ of variance; SF2 has a fronto-central distribution and accounted for $14.37 \%$ of variance; SF3 has a left anterior distribution and accounted for $6.28 \%$ of variance; SF4 has a prefrontal/frontal distribution and accounted for $24.66 \%$ of variance; and SF5 has an occipital distribution and accounted for $19.28 \%$ of variance.

The temporal PCA identified 8 TFs (see Supplementary Fig. 2). Our analysis focused on the TFs observed in the latency window around $300 \mathrm{~ms}$. Confirming the notion that both irrelevant and deviant stimuli may elicit a P3a and a P3b (e.g., Delplanque et al., 2006; Spencer et al., 2001), two separate factors ${ }^{4}$ were identified in the P3 latency window: the TF5 (with high loadings at the $250-350 \mathrm{~ms}$ latency window and with the largest factor scores at SF2, corresponding to the P3a in the voltage data), explaining $9.64 \%$ of variance, and the TF2 (with high loadings at the 351-450 ms latency window and with the largest factor scores at SF1, corresponding to the $\mathrm{P} 3 \mathrm{~b}$ in the voltage data), explaining $13.38 \%$ of variance. We exported mean amplitude based on these two intervals. Amplitude was analyzed with repeated- measures ANOVA, testing the effects of the within-subject factors of task-relevance (2 levels: standard; target), emotion (3 levels: neutral vocalizations, laughs, growls), and ROI (5 levels: frontal [Fz/3/4]; fronto-central [FCz/FC3/ FC4]; central $[\mathrm{Cz} / \mathrm{C} 3 / \mathrm{C} 4]$; centro-parietal $[\mathrm{CPz} / \mathrm{CP} 3 / \mathrm{CP} 4]$; parietal $[\mathrm{Pz} / \mathrm{P} 3 / \mathrm{P} 4])$.

P3a: Amplitude was more positive for targets relative to standards (task-relevance effect $-F(1,18)=53.032, p<0.001, \eta_{p}{ }^{2}=0.747$ ). Furthermore, a significant emotion effect $(F(2,36)=25.651$, $p<0.001, \eta_{p}^{2}=0.588$ ) revealed differences between neutral and emotional vocal cues: activity was more positive for laughs $(p<0.001)$ and growls $(p<0.001)$ compared to neutral vocal sounds, whereas no differences were observed between happy and angry cues $(p<0.05)$.

P3b: A main effect of task-relevance $(F(1,18)=103.734$, $p<.001, \eta_{p}{ }^{2}=0.852$ ) indicated more positive amplitude for targets relative to standards. Importantly, a significant interaction between task-relevance and emotion factors $(F(2,36)=4.231, p=0.022$, $\eta_{p}{ }^{2}=0.190$ ) revealed emotion-related differences in the processing of targets: activity was increased for laughs relative to neutral vocal

${ }^{4}$ The spatiotemporal distribution of the early and late P3 effects confirm the typical distribution observed for the $\mathrm{P} 3 \mathrm{a}$ and $\mathrm{P} 3 \mathrm{~b}$ responses: earlier fronto-central positivity (P3a) and later centro-parietal positivity (P3b), respectively. sounds $(p=0.001)$, and for laughs relative to growls $(p=0.003)$.

\subsubsection{Pre-stimulus induced alpha power}

Fig. 3 illustrates topographic maps of alpha power in the $250 \mathrm{~ms}$ before stimulus onset. Variation of alpha power over time is shown in Fig. 4, together with time-frequency maps for each emotional condition as a function of task-relevance.

We analyzed pre-stimulus non-phase locked frontal alpha power (at electrodes AF3, AFz, AF4, F1, F2) by testing the effects of the withinsubject factors of task-relevance ( 2 levels) and emotion ( 3 levels). The effect of task-relevance approached significance $(F(1,18)=4.233$, $\left.p=0.054, \eta_{p}{ }^{2}=0.190\right)$, indicating a tendency for decreased power in response to targets compared to non-targets (alpha desynchronization). The analysis also yielded a significant task-relevance by emotion interaction $\left(F(2,36)=4.089, p=0.025, \eta_{p}{ }^{2}=0.185\right)$ : of note, alpha desynchronization was significant for task-relevant laughs only $(p=0.036)$.

\subsection{The association between pre-stimulus alpha oscillations, $P 3 a / P 3 b$ amplitude, and affective ratings}

We probed the relative influence of pre-stimulus alpha oscillations and affective ratings on the $\mathrm{P} 3$ complex (P3a and P3b) by means of separate multiple linear regression analyses for each emotional vocalization. Multiple linear regression was computed by regressing P3a amplitude (at FCz electrode) against mean pre-stimulus alpha power (mean power of the electrodes included in the statistical analysis) and valence and arousal ratings for each specific emotional vocalization using a forced entry method. The same method was repeated for P3b amplitude (at Pz electrode). No significant associations were observed in the case of P3a for both positive and negative vocalizations $(p>0.05)$. However, P3b amplitude for laughs was significantly predicted by valence ratings ( $p=0.042$ ) and pre-stimulus alpha power $(p=0.022)$ : the more pleasant the vocal sounds were perceived, and the less positive the alpha power, the larger the $\mathrm{P} 3 \mathrm{~b}$ amplitude for vocal targets (see Table 3). No significant associations were observed in the case of growls $(p>0.05)$.

We also probed the relative influence of affective ratings on prestimulus alpha power through separate multiple linear regression analyses for each emotional vocalization. The findings indicated that the variability of pre-stimulus alpha power was not accounted for by the perceived valence or arousal of the vocalizations $(p>0.05)$.

\section{Discussion}

Being able to selectively attend to salient and novel cues in the sensory environment is at the root of human cognition and social interactions. The current study probed the interactions between attention and emotion during voice processing, by combining ERP, time-frequency, and behavioral data.

The idea that emotion modulates attention is not new and has been consistently reported in visual studies (see Olofsson, Nordin, Sequeira, \& Polich, 2008 for a review of affective picture processing). However, similar investigations using emotional vocalizations have remained sparse. In line with previous studies (Delplanque et al., 2006; Spencer et al., 2001), we observed that both a P3a and P3b were elicited in response to rare target vocalizations. The observation of two dissociable components in the P3 window corroborates the hypothesis that these components reflect different cognitive processes (Friedman, Cycowicz, \& Gaeta, 2001). Further, we observed that the P3b response was predicted by pre-stimulus induced alpha power and by the perceived pleasantness of the stimulus. These findings are discussed below.

\subsection{Attentional effects during vocal emotional processing: ERP evidence}

Corroborating previous studies, our findings suggest that attention 


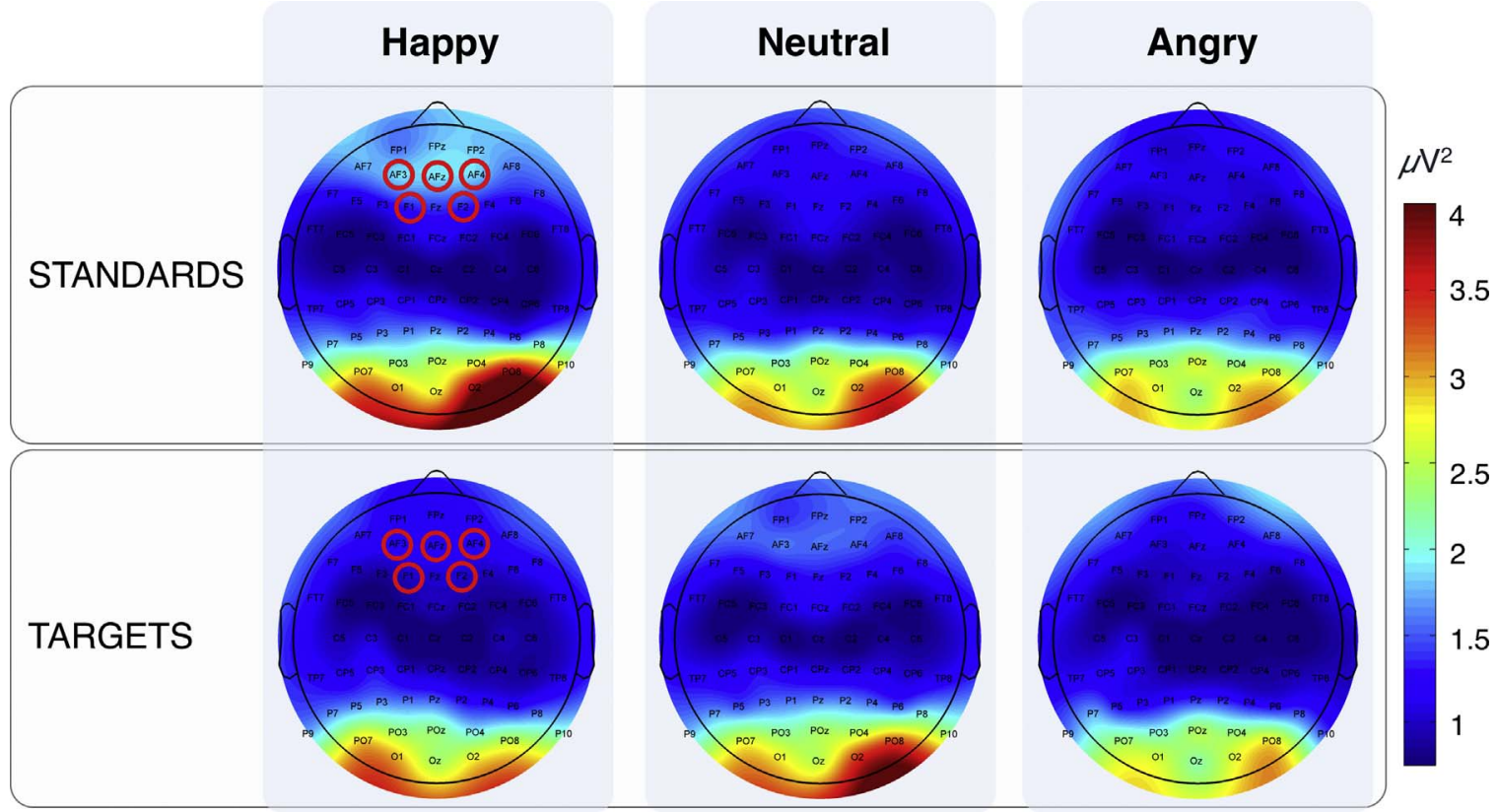

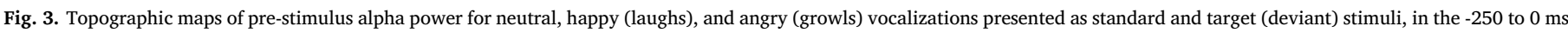
pre-stimulus window.

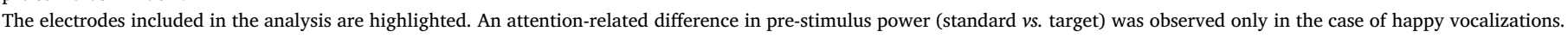

\section{A. Alpha power variation over time}

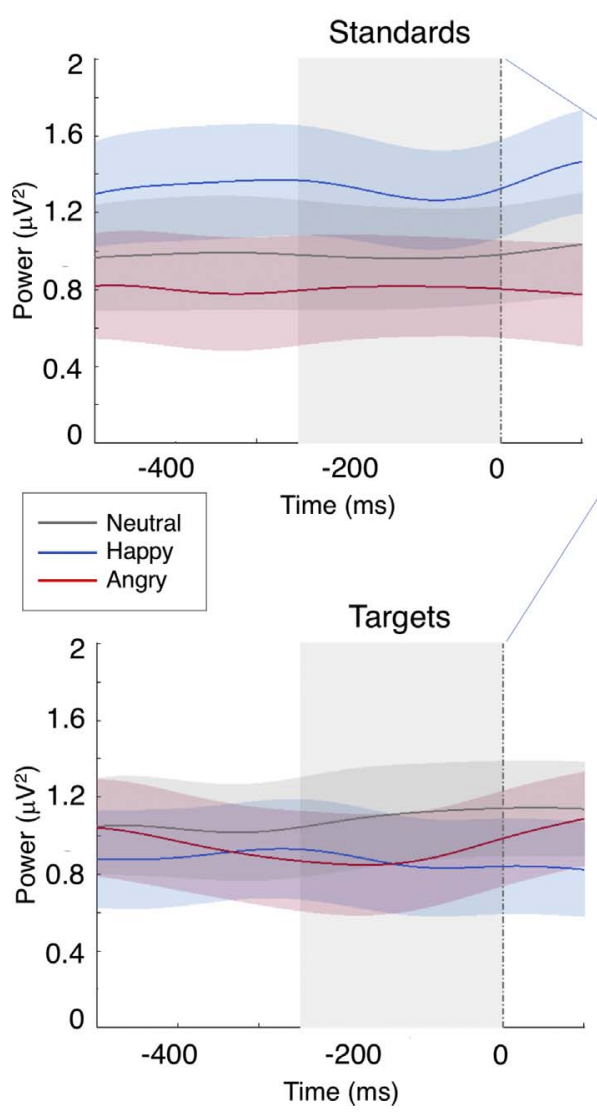

B. Standards and Targets
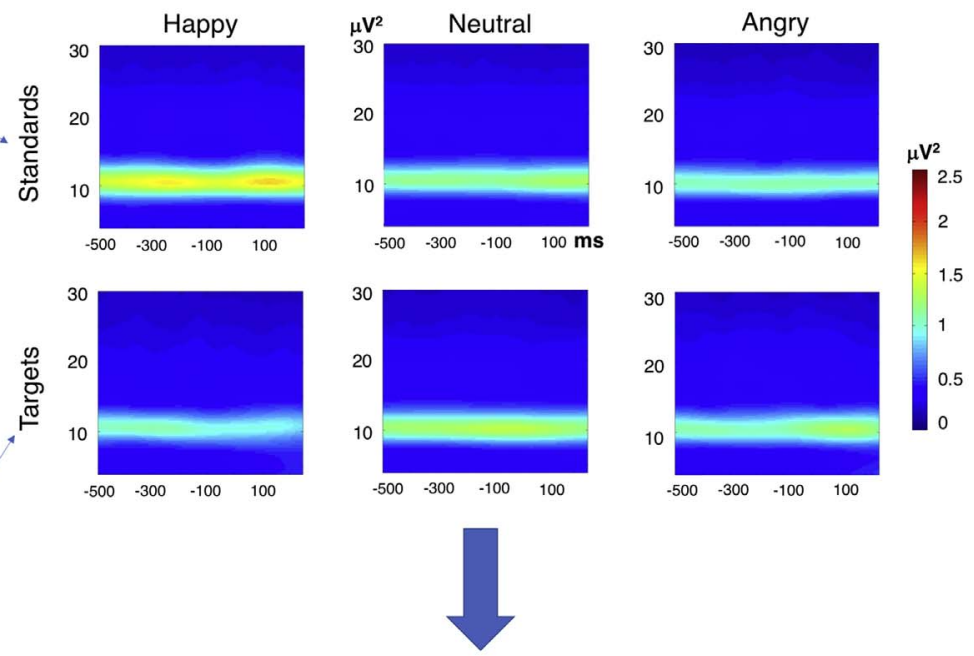

\section{Targets - Standards (difference)}
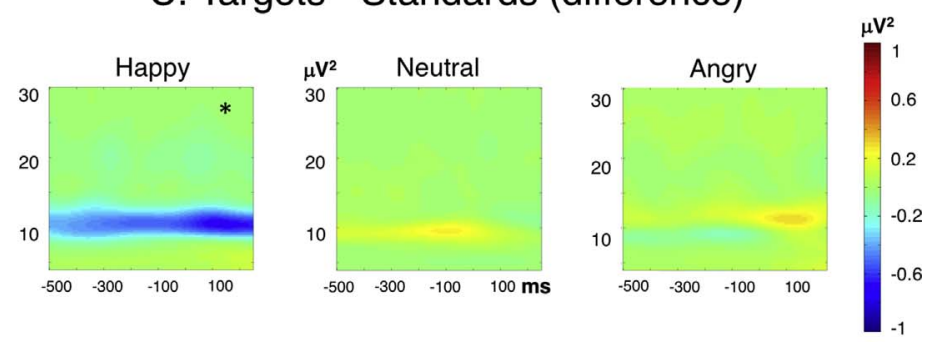

Fig. 4. Pre-stimulus alpha power.

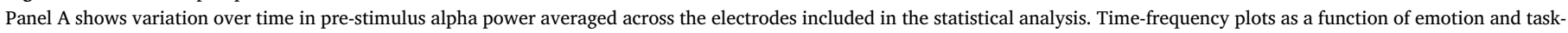

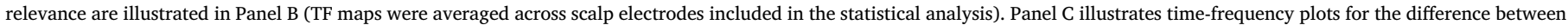
standards and targets as a function of emotion type (statistically significant differences are marked by asterisks). 
Table 3

Summary of Linear Regression Analyses of Pre-stimulus Alpha Power and Affective Ratings as Predictors for P3b Amplitude.

\begin{tabular}{|c|c|c|c|c|c|c|}
\hline \multirow{3}{*}{$\begin{array}{l}\text { Dependent } \\
\text { Variable }\end{array}$} & \multicolumn{6}{|l|}{ Predictor } \\
\hline & \multicolumn{2}{|c|}{ Pre-stimulus alpha power ${ }^{\mathrm{a}}$} & \multicolumn{2}{|c|}{ Valence } & \multicolumn{2}{|l|}{ Arousal } \\
\hline & $B$ & $t$ & $B$ & $t$ & $B$ & $t$ \\
\hline $\begin{array}{l}\text { P3b - } \\
\quad \text { Laughs }\end{array}$ & -3.909 & $-2.572^{*}$ & 1.185 & $2.239 *$ & -0.142 & -0.690 \\
\hline $\begin{array}{l}\text { P3b - } \\
\text { Growls }\end{array}$ & 0.522 & 0.412 & 0.178 & 0.720 & 0.323 & 1.215 \\
\hline
\end{tabular}

Note. $\beta$ values, $\mathrm{t}$ scores, and significance levels are provided for each vocal emotion with respect to predictor. ${ }^{*} p<0.05$.

a Averaged power at electrodes $\mathrm{AF} 3, \mathrm{AFz}, \mathrm{AF} 4, \mathrm{~F} 1$, and F2.

is not static but oscillates over time as a function of task-relevance and valence. The spatio-temporal decomposition of the EEG signal revealed a two-fold response to vocal changes: 1) stimulus-driven attention orienting that was mainly modulated by the perceived arousal of the voice (P3a); 2) top-down allocation of attentional resources for subsequent update of an internal model of the environment after the evaluation of stimulus salience, which was primarily modulated by the perceived valence of the voice (P3b). Therefore, valence and arousal affected different stages of stimulus processing in a specific way: whereas the fronto-central P3a indexed a general discrimination between salient and non-salient vocal cues (with attention being enhanced for emotional targets), the centro-parietal P3b reflected the modulatory effects of valence, being increased in response to happy targets.

An early (before $300 \mathrm{~ms}$ ) discrimination between emotional and non-emotional vocal cues, irrespective of valence, agrees with previous auditory studies (e.g., Pinheiro et al., 2016). This effect demonstrates the sensitivity of the P3a to the emotional arousal of a vocal stimulus, such that attention is more effectively switched to stimuli tagged as "salient" or highly arousing compared to low arousing (neutral) stimuli. A finer discrimination takes place in a later stage (after $300 \mathrm{~ms}$ ), in which positive and negative vocalizations are distinguished. The increased P3b response to happy vocal targets suggests that top-down attentional resources for subsequent memory processing were more strongly allocated towards task-relevant vocal sounds with a positive quality. This finding seems at odds with previous results from emotional picture studies, challenging the prevalent view that negative emotional stimuli are more salient than positive ones (e.g., Ito et al., 1998; Smith, Cacioppo, Larsen, \& Chartrand, 2003). They also contrast with the observation that the $\mathrm{P} 3 \mathrm{~b}$ is sensitive to arousal (i.e., enhanced for negative and positive pictures compared to neutral ones), whereas the P3a is modulated by valence (i.e., enhanced for negative pictures) (Delplanque et al., 2006).

It is worth noting that evidence for a negativity bias in emotion perception has been mixed. Whereas some studies reported facilitated processing of negative compared to positive stimuli (reflected for example in increased P3/Late Positive Potential for negative cues - e.g., Delplanque et al., 2006; Ito et al., 1998), others found that the processing of negative and positive stimuli is similar (reflected for example in increased P3/Late Positive Potential for both types of emotional stimuli compared to neutral stimuli - e.g., Briggs \& Martin, 2009; Diedrich, Naumann, Maier, Becker, \& Bartussek, 1997; Palomba, Angrilli, \& Mini, 1997; Weinberg \& Hajcak, 2010). Specifically, the negativity bias fails to materialize when pleasant and unpleasant stimuli have similar motivational relevance, i.e. when depicting biological imperatives (Hilgard, Weinberg, Hajcak Proudfit, \& Bartholow, 2014; Weinberg \& Hajcak, 2010). Other studies provided evidence for facilitated processing of positive compared to negative stimuli (Herbert, Junghofer, \& Kissler, 2008; Johnstone et al., 2006; Kanske \& Kotz, 2007; Pinheiro, Barros, Vasconcelos, Obermeier, \& Kotz, 2017) similarly to the current study. For example, positive emotions have been linked to a broadened attention scope (Fredrickson \& Branigan, 2005). The aging literature suggests that the positivity effect (the privileged processing of positive compared to negative information) is influenced by the experimental task (the effect emerges more consistently when experimental tasks do not involve automatic processing and stimulus processing is not constrained by task instructions, such as when the task does not require active memorization of the stimuli), and when the personal relevance of the stimulus is controlled for (reviewed in Reed \& Carstensen, 2012).

Because of its relevance in social interactions, such as in social bonding, laughter may represent a predominantly relevant social signal. For example, Johnstone et al. (2006) found greater activation of the amygdala and the insula in response to happy than to angry vocalizations when participants were explicitly instructed to attend to these vocalizations. The authors suggested happy vocal expressions are particularly salient social signals, whose function is well manifested in social interactions (Johnstone et al., 2006). Using pictures, Hilgard et al. (2014) observed a negativity bias but only when the positive counterparts were thrilling, rather than affiliative, pleasant stimuli. Corroborating the association between selective attention and subjective stimulus relevance, a regression analysis showed that the enhanced P3b response to happy targets was predicted by the perceived pleasantness of the voice. The current findings indicate stronger responsiveness to social affiliative emotions such as laughter (Scott, Lavan, Chen, \& McGettigan, 2014), and provide further support for dissociable neural pathways involved in the processing of distinct discrete emotions (e.g., Harmer, Thilo, Rothwell, \& Goodwin, 2001; Ikeda \& Watanabe, 2009; Kilts et al., 2003; Kotz, Kalberlah, Bahlmann, Friederici, \& Haynes, 2013).

The affect-biased attention hypothesis may represent a plausible explanation for the current results. Top-down processes may bias attention toward motivationally relevant features of the environment before the presentation of a stimulus: sensory systems are then tuned to incoming information based on what is motivationally relevant for the individual in a given context (Todd, Cunningham, Anderson, \& Thompson, 2012) and based on previous experience (Pollak \& Tolley-Schell, 2003). Hence, affect-biased attention may be considered a specific form of selective attention (Todd et al., 2012). In particular, tasks that involve detecting a specific target among distractors (as in the current study) are considered to represent a better measure of affect-biased attention (or pre-stimulus filtering) (Todd et al., 2012). An attentional bias toward rewarding stimuli (such as laughter) has been associated with personality traits such as extraversion (Hakamata et al., 2010). Even though this is speculative, future studies should probe the role of individual differences, such as personality, in selective attention to emotional vocalizations.

\subsection{Attentional effects during vocal emotional processing: neural oscillatory evidence}

Recent evidence suggests that perception also depends on the internal brain state before the presentation of a stimulus (e.g., Kayser, McNair, \& Kayser, 2016). We expected to find an influence of pre-stimulus alpha activity on target processing (related to the maintenance of target information in an attentional buffer - e.g., Klimesch, 2012), but it remained unclear whether these effects would be mediated by stimulus valence. In the current study, we observed that pre-stimulus alpha nonphase locked power was reduced only in response to task-relevant (target) compared to task-irrelevant (standard) happy vocalizations. This finding suggests that anticipatory attention is enhanced for stimuli with positive valence. Even though targets appeared with the same probability in the different experimental blocks, expectations based on internal models of the probability with which sound should appear were more effective as a function of perceived stimulus relevance. Support for this interpretation comes from previous studies showing that the amount of alpha desynchronization is related to the relevance 
of a task (Klimesch, 1999) and to stimulus salience (e.g., Babiloni et al., 2004; Hartmann, Schlee, \& Weisz, 2012): the more relevant the stimulus is to the task or to the subject (i.e., its emotional value), the stronger the amount of alpha suppression.

The present findings are interesting on a number of accounts. First, they provide further support for the role of alpha oscillations in the continuous monitoring of internally generated auditory expectations (e.g., Gross et al., 2006). Second, they indicate that the modulatory effects of pre-stimulus oscillatory power are not general or non-specific but rather can depend on the emotional quality of a stimulus.

\subsection{The relationship between pre-stimulus alpha power, P3, and affective ratings}

Supporting the role of pre-stimulus alpha activity in modulating the brain network when preparing for the processing of upcoming stimuli (e.g., Rajagovindan \& Ding, 2011; reviewed in Jensen \& Mazaheri, 2010), our study evinced a functional relationship between pre-stimulus induced alpha power, the $\mathrm{P} 3 \mathrm{~b}$ response and affective ratings of the vocal sounds (see Ishii et al., 2009; Jasiukaitis \& Hakerem, 1988; Polich, 2007; Yordanova, Kolev, \& Polich, 2001 for evidence suporting the relationship between P3 and alpha oscillations). Specifically, an increased P3b response was predicted by the amount of pre-stimulus alpha power, as well as by the perceived pleasantness of the vocalizations.

Previous studies make a strong case for the role of pre-stimulus oscillatory activity in modulating performance in stimulus discrimination and stimulus detection (e.g., Haegens, Handel, \& Jensen, 2011; Haegens, Luther, \& Jensen, 2012). In particular, anticipatory attention reflected in alpha-band desynchronization was shown to improve the processing of task-relevant stimuli (e.g., Rohenkohl \& Nobre, 2011). If you were told to count happy sounds, you would hold information about what a happy sound is in working memory, and this could automatically facilitate the processing of features related to happy stimuli, while inhibiting irrelevant information (e.g., visual). As confirmed by a very large number of studies, attention is biased as we focus our resources on information that is most relevant to our current goals and needs, whereas suppressing irrelevant information simultaneously. In the current study, larger expectation-driven effects reflected in prestimulus alpha power predicted enhanced P3b amplitude, indicating that pre-stimulus alpha activity may shape voice perception through expectancy. Nonetheless, it is worth noting that this relationship was specific of positive vocalizations (laughter).

Compared to previous results in which emotional vocalizations were processed under different task conditions (e.g., the same vocalizations used in the current study but presented as infrequent and task-irrelevant stimuli - Pinheiro et al., 2016), the current findings show that the type of task (e.g., task-relevant vs. task-irrelevant stimuli) and associated attention focus (towards the vocal stimuli or away from the vocal stimuli) have an impact upon how vocal emotions are perceived and processed. Specifically, they suggest that the cognitive evaluation of the emotional significance of the voice occurs differently depending on both task and stimulus factors. Therefore, these effects need to be accounted for by multi-stage models of vocal emotional processing (e.g., Schirmer \& Kotz, 2006).

It is worth noting that the focus of the current study was on the P3 and on pre-stimulus alpha power. Further studies should probe whether the preferential processing of positive vocalizations is also reflected in other ERP components and oscillatory measures (we recently found enhanced Mismatch Negativity for laughs compared to growls and neutral vocalizations - Pinheiro et al., 2017).

\section{Conclusion}

The current study aimed at investigating how emotion and attention interact during the processing of nonverbal vocalizations, combining
ERP, EEG time-frequency and behavioral analyses. Both ERP and alpha power confirmed the modulatory role of emotion in attention to vocal stimuli. More specifically, attention orienting was modulated by stimulus arousal and enhanced for both laughs and growls compared to neutral vocalizations (P3a); top-down attentional resources and memory updating were modulated by stimulus valence and more strongly engaged by laughs compared to growls and neutral vocal stimuli (P3b). The P3b response to happy targets was preceded and predicted by increased alpha desynchronization, as well as by the perceived pleasantness of the vocal cues.

In essence, our findings demonstrate that the emotional properties of the voice (valence and arousal) modify different stages of attention. Further, they highlight the need to consider both task and stimulus effects in current models of vocal emotional processing.

\section{Acknowledgments}

This work was supported by Grants IF/00334/2012, PTDC/MHNPCN/3606/2012, and PTDC/ MHC-PCN/0101/2014 funded by the Science and Technology Foundation (Fundacão para a Ciência e a Tecnologia - FCT, Portugal) and FEDER (European Regional Development Fund) through the European programs QREN (National Strategic Reference Framework), and COMPETE (Operational Programme 'Thematic Factors of Competitiveness'), awarded to A.P.P (IF/ 00334/2012, PTDC/MHN-PCN/ 3606/2012, PTDC/MHC-PCN/ 0101/2014) and S.A.K. (PTDC/ MHN-PCN/3606/2012, PTDC/MHCPCN/0101/2014).

\section{Appendix A. Supplementary data}

Supplementary data associated with this article can be found, in the online version, at http://dx.doi.org/10.1016/j.biopsycho.2017.09.012.

\section{References}

Adolphs, R. (2002). Neural systems for recognizing emotion. Current Opinion in Neurobiology, 12(2), 169-177. http://dx doi.org/10.1016/S0959-4388(02)00301-X. American Psychiatric Association (2000). Diagnostic and statistical manual of mental disorders. Washington, DC: American Psychiatric Association Presshttp://dx.doi.org/10. 1016/B978-1-4377-2242-0.00016-X.

Babiloni, C., Brancucci, A., Arendt-Nielsen, L., Babiloni, F., Capotosto, P., Carducci, F., .. Chen, A. C. N. (2004). Attentional processes and cognitive performance during expectancy of painful galvanic stimulations: A high-resolution EEG study. Behavioural Brain Research, 152(1), 137-147. http://dx.doi.org/10.1016/j.bbr.2003.10.004.

Balconi, M., Falbo, L., \& Brambilla, E. (2009). BIS/BAS responses to emotional cues: Self report, autonomic measure and alpha band modulation. Personality and Individual Differences, 47(8), 858-863. http://dx.doi.org/10.1016/j.paid.2009.07.004.

Banse, R., \& Scherer, K. R. (1996). Acoustic profiles in vocal emotion expression. Journal of Personality and Social Psychology, 70(3), 614-636. http://dx.doi.org/10.1037/ 0022-3514.70.3.614.

Bastiaansen, M. C. M., \& Brunia, C. H. M. (2001). Anticipatory attention: An event-related desynchronization approach. International Journal of Psychophysiology, 43(1), 91-107. http://dx.doi.org/10.1016/S0167-8760(01)00181-7.

Belin, P., Zatorre, R. J., Lafaille, P., Ahad, P., \& Pike, B. (2000). Voice-selective areas in human auditory cortex. Nature, 403(6767), 309-312. http://dx.doi.org/10.1038/ 35002078.

Belin, P., Fillion-Bilodeau, S., \& Gosselin, F. (2008). The Montreal affective voices: A validated set of nonverbal affect bursts for research on auditory affective processing. Behavior Research Methods, 40(2), 531-539. http://dx.doi.org/10.3758/BRM.40.2. 531.

Bernat, E., Bunce, S., \& Shevrin, H. (2001). Event-related brain potentials differentiate positive and negative mood adjectives during both supraliminal and subliminal visual processing. International Journal of Psychophysiology, 42(1), 11-34. http://dx.doi.org/ 10.1016/S0167-8760(01)00133-7.

Bestelmeyer, P. E. G., Maurage, P., Rouger, J., Latinus, M., \& Belin, P. (2014). Adaptation to vocal expressions reveals multistep perception of auditory emotion. Journal of Neuroscience, 34(24), 8098-8105. http://dx.doi.org/10.1523/JNEUROSCI.4820-13. 2014.

Blair, R. J. R., Morris, J. S., Frith, C. D., Perrett, D. I., \& Dolan, R. J. (1999). Dissociable neural responses to facial expressions of sadness and anger. Brain, 122(5), 883-893. http://dx.doi.org/10.1093/brain/122.5.883.

Boersma, P., \& Weenink, D. (2013). Praat: Doing phonetics by computer [computer program] Version 5.3.53. Retrieved from http://www.praat.org/.

Bradley, M., \& Lang, P. J. (1994). Measuring emotion: The self-assessment manikin and the semantic differential. Journal of Behavior Therapy and Experimental Psychiatry, 
25(I) 49-59. http://dx doi.org/10.1016/0005-7916(94)90063-9.

Briggs, K. E., \& Martin, F. H. (2009). Affective picture processing and motivational relevance: Arousal and valence effects on ERPs in an oddball task. International Journal of Psychophysiology, 72(3), 299-306. http://dx.doi.org/10.1016/j.ijpsycho.2009.01. 009.

Brosch, T., Grandjean, D., Sander, D., \& Scherer, K. R. (2009). Cross-modal emotional attention: Emotional voices modulate early stages of visual processing. Journal of Cognitive Neuroscience, 21(9), 1670-1679. http://dx.doi.org/10.1162/jocn.2009. 21110.

Brosch, T., Grandjean, D., Sander, D., \& Scherer, K. R. (2008). Behold the voice of wrath: Cross-modal modulation of visual attention by anger prosody. Cognition, 106(3), 1497-1503. http://dx.doi.org/10.1016/j.cognition.2007.05.011.

Brosch, T., Sander, D., Pourtois, G., \& Scherer, K. R. (2008). Beyond fear: Rapid spatial orienting toward positive emotional stimuli. Psychological Science, 19(4), 362-370. http://dx.doi.org/10.1111/j.1467-9280.2008.02094.x.

Campanella, S., Bruyer, R., Froidbise, S., Rossignol, M., Joassin, F., Kornreich, C., \& Verbanck, P. (2010). Is two better than one? A cross-modal oddball paradigm reveals greater sensitivity of the P300 to emotional face-voice associations. Clinical Neurophysiology, 121(11), 1855-1862. http://dx.doi.org/10.1016/j.clinph.2010.04. 004.

Canavarro, M. C. (1999). Inventário de Sintomas Psicopatológicos [Brief Symptoms Inventory]: BSI. In L. S. A. M. R. Simões, \& M. Gonçalves (Vol. Eds.), Testes e provas psicológicas em Portugal [Psychological Tests in Portugal]: Vol. II. Braga: SHO/APPORT.

Cattell, R. B. (1966). The scree test for the number of factors. Multivariate Behavioral Research, 1(2), 245-276. http://dx.doi.org/10.1207/s15327906mbr0102 10.

Cohen, M. X., \& Donner, T. H. (2013). Midfrontal conflict-related theta-band power reflects neural oscillations that predict behavior. Journal of Neurophysiology, 110(12), 2752-2763. http://dx.doi.org/10.1152/jn.00479.2013.

Courchesne, E., Hillyard, S. A., \& Galambos, R. (1975). Stimulus novelty, task relevance and the visual evoked potential in man. Electroencephalography and Clinical Neurophysiology, 39(2), 131-143. http://dx.doi.org/10.1016/0013-4694(75) 90003-6.

David, O., Kilner, J. M., \& Friston, K. J. (2006). Mechanisms of evoked and induced responses in MEG/EEG. Neuroimage, 31(4), 1580-1591. http://dx.doi.org/10.1016/j neuroimage.2006.02.034.

Deiber, M.-P., Missonnier, P., Bertrand, O., Gold, G., Fazio-Costa, L., Ibañez, V., \& Giannakopoulos, P. (2007). Distinction between perceptual and attentional processing in working memory tasks: A study of phase-locked and induced oscillatory brain dynamics. Journal of Cognitive Neuroscience, 19, 158-172. http://dx.doi.org/10.1162/ jocn.2007.19.1.158.

Delorme, A., \& Makeig, S. (2004). EEGLAB: An open source toolbox for analysis of singletrial EEG dynamics including independent component analysis. Journal of Neuroscience Methods, 134(1), 9-21. http://dx.doi.org/10.1016/j.jneumeth.2003.10. 009.

Delplanque, S., Silvert, L., Hot, P., Rigoulot, S., \& Sequeira, H. (2006). Arousal and valence effects on event-related P3a and P3b during emotional categorization. International Journal of Psychophysiology, 60(3), 315-322. http://dx.doi.org/10.1016/ j.ijpsycho.2005.06.006.

Diedrich, O., Naumann, E., Maier, S., Becker, G., \& Bartussek, D. (1997). A frontal positive slow wave in the ERP associated with emotional slides. Journal of Psychophysiology, 11(1), 71-84

Donchin, E., \& Coles, M. G. H. (1988). Is the P300 component a manifestation of context updating? Behavioral and Brain Sciences, 11(3), 357. http://dx.doi.org/10.1017/ S0140525X00058027.

Donchin, E. (1981). Surprise!...Surprise? Psychophysiology, 18, 493-513. http://dx.doi. org/10.1111/j.1469-8986.1981. tb01815.x.

Eimer, M., \& Holmes, A. (2007). Event-related brain potential correlates of emotional face processing. Neuropsychologia, 45(1), 15-31. http://dx.doi.org/10.1016/j neuropsychologia.2006.04.022

Frühholz, S., \& Grandjean, D. (2013). Processing of emotional vocalizations in bilateral inferior frontal cortex. Neuroscience and Biobehavioral Reviews, 37(10), 2847-2855. http://dx.doi.org/10.1016/j.neubiorev.2013.10.007.

Frühholz, S., Ceravolo, L., \& Grandjean, D. (2012). Specific brain networks during explicit and implicit decoding of emotional prosody. Cerebral Cortex, 22(5), 1107-1117. http://dx.doi.org/10.1093/cercor/bhr184.

Fredrickson, B. L., \& Branigan, C. (2005). Positive emotions broaden the scope of attention and thought-action repertoires. Cognition \& Emotion, 19(3), 313-332. http://dx. doi.org/10.1080/02699930441000238.

Friedman, D., Cycowicz, Y. M., \& Gaeta, H. (2001). The novelty P3: An event-related brain potential (ERP) sign of the brain's evaluation of novelty. Neuroscience and Biobehavioral Reviews, 25(4), 355-373. http://dx.doi.org/10.1016/S0149-7634(01) 00019-7.

Goldstein, A., Spencer, K. M., \& Donchin, E. (2002). The influence of stimulus deviance and novelty on the P300 and novelty P3. Psychophysiology, 39(6), 781-790. http://dx. doi.org/10.1017/S004857720201048X.

Goydke, K. N., Altenmüller, E., Möller, J., \& Münte, T. F. (2004). Changes in emotiona tone and instrumental timbre are reflected by the mismatch negativity. Cognitive Brain Research, 21(3), 351-359. http://dx.doi.org/10.1016/j.cogbrainres.2004.06. 009

Grandjean, D., Sander, D., Pourtois, G., Schwartz, S., Seghier, M. L., Scherer, K. R., \& Vuilleumier, P. (2005). The voices of wrath: Brain responses to angry prosody in meaningless speech. Nature Neuroscience, 8(2), 145-146. http://dx.doi.org/10.1038/ nn1392.

Gross, J., Schmitz, F., Schnitzler, I., Kessler, K., Shapiro, K., Hommel, B., \& Schnitzler, A. (2006). Anticipatory control of long-range phase synchronization. European Journal of Neuroscience, 24(7), 2057-2060. http://dx.doi.org/10.1111/j.1460-9568.2006. 05082x.

Haegens, S., Handel, B. F., \& Jensen, O. (2011). Top-down controlled alpha band activity in somatosensory areas determines behavioral performance in a discrimination task. Journal of Neuroscience, 31(14), 5197-5204. http://dx.doi.org/10.1523/JNEUROSCI. 5199-10.2011.

Haegens, S., Luther, L., \& Jensen, O. (2012). Somatosensory anticipatory alpha activity increases to suppress distracting input. Journal of Cognitive Neuroscience, 24(3), 677-685. http://dx.doi.org/10.1162/jocn_a_00164.

Hakamata, Y., Lissek, S., Bar-Haim, Y., Britton, J. C., Fox, N. A., Leibenluft, E., ... Pine, D. S. (2010). Attention bias modification treatment: A meta-analysis toward the establishment of novel treatment for anxiety. Biological Psychiatry, 68(11), 982-990. http://dx.doi.org/10.1016/j.biopsych.2010.07.021.

Harmer, C. J., Thilo, K. V., Rothwell, J. C., \& Goodwin, G. M. (2001). Transcranial magnetic stimulation of medial-frontal cortex impairs the processing of angry facial expressions. Nature Neuroscience, 4(1), 17-18. http://dx.doi.org/10.1038/82854.

Hartmann, T., Schlee, W., \& Weisz, N. (2012). It's only in your head: Expectancy of aversive auditory stimulation modulates stimulus-induced auditory cortical alpha desynchronization. Neuroimage, 60(1), 170-178. http://dx.doi.org/10.1016/j. neuroimage.2011.12.034.

Hawk, S. T., Van Kleef, G. A., Fischer, A. H., \& van Der Schalk, J. (2009). Worth a thousand words: Absolute and relative decoding of nonlinguistic affect vocalizations. Emotion, 9(3), 293-305. http://dx.doi.org/10.1037/a0015178.

Herbert, C., Junghofer, M., \& Kissler, J. (2008). Event related potentials to emotional adjectives during reading. Psychophysiology, 45(3), 487-498. http://dx.doi.org/10 1111/j.1469-8986.2007.00638.x.

Hilgard, J., Weinberg, A., Hajcak Proudfit, G., \& Bartholow, B. D. (2014). The negativity bias in affective picture processing depends on top-down and bottom-up motivational significance. Emotion, 14(5), 940-949. http://dx.doi.org/10.1037/a0036791.

Hipp, J. F., \& Siegel, M. (2013). Dissociating neuronal gamma-band activity from cranial and ocular muscle activity in EEG. Frontiers in Human Neuroscience, 7, 338. http://dx. doi.org/10.3389/fnhum.2013.00338.

Ikeda, H., \& Watanabe, K. (2009). Anger and happiness are linked differently to the explicit detection of biological motion. Perception, 38(7), 1002-1011. http://dx.doi. org $/ 10.1068 / \mathrm{p} 6250$.

Ishii, R., Canuet, L., Herdman, A., Gunji, A., Iwase, M., Takahashi, H., ... Takeda, M. (2009). Cortical oscillatory power changes during auditory oddball task revealed by spatially filtered magnetoencephalography. Clinical Neurophysiology, 120(3), 497-504. http://dx.doi.org/10.1016/j.clinph.2008.11.023.

Ito, T., \& Cacioppo, J. (2005). Variations on a human universal: Individual differences in positivity offset and negativity bias. Cognition \& Emotion, 19(1), 1-26. http://dx.doi. org/10.1080/02699930441000120.

Ito, T. A., Larsen, J. T., Smith, N. K., \& Cacioppo, J. T. (1998). Negative information weighs more heavily on the brain: The negativity bias in evaluative categorizations. Journal of Personality and Social Psychology, 75(4), 887-900. http://dx.doi.org/10. 1037/0022-3514.75.4.887.

Jasiukaitis, P., \& Hakerem, G. (1988). The effect of prestimulus alpha activity on the P300. Psychophysiology, 25, 157-165. http://dx.doi.org/10.1111/j.1469-8986.1988. tb00979.x.

Jensen, O., \& Mazaheri, A. (2010). Shaping functional architecture by oscillatory alpha activity: Gating by inhibition. Frontiers in Human Neuroscience, 4, 186. http://dx.doi. org/10.3389/fnhum.2010.00186.

Jessen, S., \& Kotz, S. A. (2011). The temporal dynamics of processing emotions from vocal, facial, and bodily expressions. Neuroimage, 58(2), 665-674. http://dx.doi.org/ 10.1016/j.neuroimage.2011.06.035

Johnstone, T., van Reekum, C. M., Oakes, T. R., \& Davidson, R. J. (2006). The voice of emotion: An FMRI study of neural responses to angry and happy vocal expressions. Social Cognitive and Affective Neuroscience, 1(3), 242-249. http://dx.doi.org/10.1093/ scan/nsl027.

Kanske, P., \& Kotz, S. A. (2007). Concreteness in emotional words: ERP evidence from a hemifield study. Brain Research, 1148(1), 138-148. http://dx.doi.org/10.1016/j. brainres.2007.02.044

Kayser, S. J., McNair, S. W., \& Kayser, C. (2016). Prestimulus influences on auditory perception from sensory representations and decision processes. Proceedings of the National Academy of Sciences of the United States of America, 113(17), 201524087. http://dx.doi.org/10.1073/pnas.1524087113.

Keil, A., Bradley, M. M., Hauk, O., Rockstroh, B., Elbert, T., Lang, P. J., ... Lang, P. (2002). Large-scale neural correlates of affective picture processing. Psychophysiology, 39(5), 641-649 10.1017.S0048577202394162.

Keil, A., Moratti, S., Sabatinelli, D., Bradley, M. M., \& Lang, P. J. (2005). Additive effect of emotional content and spatial selective attention on electrocortical facilitation. Cerebral Cortex, 15(8), 1187-1197. http://dx.doi.org/10.1093/cercor/bhi001.

Keren, A. S., Yuval-Greenberg, S., \& Deouell, L. Y. (2010). Saccadic spike potentials in gamma-band EEG: Characterization, detection and suppression. Neuroimage, 49(3), 2248-2263. http://dx. doi.org/10.1016/j.neuroimage.2009.10.057.

Kilts, C. D., Egan, G., Gideon, D. A., Ely, T. D., \& Hoffman, J. M. (2003). Dissociable neural pathways are involved in the recognition of emotion in static and dynamic facial expressions. Neuroimage, 18(1), 156-168.

Klimesch, W. (1999). EEG alpha and theta oscillations reflect cognitive and memory performance: A review and analysis. Brain Research Reviews, 29(2-3), 169-195. http://dx.doi.org/10.1016/S0165-0173(98)00056-3.

Klimesch, W. (2012). Alpha-band oscillations, attention, and controlled access to stored information. Trends in Cognitive Sciences, 16(12), 606-617. http://dx.doi.org/10 1016/j.tics.2012.10.007.

Klimesch, W., Doppelmayr, M., Russegger, H., Pachinger, T., \& Schwaiger, J. (1998). Induced alpha band power changes in the human EEG and attention. Neuroscience Letters, 244(2), 73-76. http://dx.doi.org/10.1016/S0304-3940(98)00122-0. 
Klimesch, W., Russegger, H., Doppelmayr, M., \& Pachinger, T. (1998). A method for the calculation of induced band power: Implications for the significance of brain oscillations. Electroencephalography and Clinical Neurophysiology, 108(2), 123-130. http:// dx.doi.org/10.1016/S0168-5597(97)00078-6.

Kotz, S. A., \& Paulmann, S. (2011). Emotion, language, and the brain. Linguistics and Language Compass, 5(3), 108-125. http://dx.doi.org/10.1111/j.1749-818X.2010. 00267.x.

Kotz, S. A., Kalberlah, C., Bahlmann, J., Friederici, A. D., \& Haynes, J. D. (2013). Predicting vocal emotion expressions from the human brain. Human Brain Mapping, 34(8), 1971-1981. http://dx.doi.org/10.1002/hbm.22041.

Kotz, S. A., Stockert, A., \& Schwartze, M. (2014). Cerebellum, temporal predictability and the updating of a mental model. Philosophical Transactions of the Royal Society of London. Series B, Biological Sciences, 369, 20130403. http://dx.doi.org/10.1098/rstb. 2013.0403

Lane, R. D., Chua, P. M. L., \& Dolan, R. J. (1999). Common effects of emotional valence, arousal and attention on neural activation during visual processing of pictures. Neuropsychologia, 37(9), 989-997. http://dx.doi.org/10.1016/S0028-3932(99) 00017-2.

Neuper, C., \& Pfurtscheller, G. (2001). Event-related dynamics of cortical rhythms: Frequency-specific features and functional correlates. International Journal of Psychophysiology, 43(1), 41-58. http://dx.doi.org/10.1016/S0167-8760(01)00178-7.

Noonan, M. P., Nika, A., Pike, A., Printzlau, F., Crittenden, B. M., \& Stokes, M. G. (2016). Distinct mechanisms for distractor suppression and target facilitation. Journal of Neuroscience, 36(6), 1797-1807. http://dx.doi.org/10.1523/JNEUROSCI.2133-15. 2016.

Oldfield, R. C. (1971). The assessment and analysis of handedness: The Edinburgh inventory. Neuropsychologia, 9(1), 97-113. http://dx.doi.org/10.1016/0028-3932(71) 90067-4.

Olofsson, J. K., Nordin, S., Sequeira, H., \& Polich, J. (2008). Affective picture processing: An integrative review of ERP findings. Biological Psychology, 77(3), 247-265. http:// dx.doi.org/10.1016/j.biopsycho.2007.11.006.

Palomba, D., Angrilli, A., \& Mini, A. (1997). Visual evoked potentials, heart rate responses and memory to emotional pictorial stimuli. International Journal of Psychophysiology, 27(1), 55-67. http://dx.doi.org/10.1016/S0167-8760(97)00751-4.

Paulmann, S., \& Kotz, S. A. (2008a). An ERP investigation on the temporal dynamics of emotional prosody and emotional semantics in pseudo- and lexical-sentence context. Brain and Language, 105(1), 59-69. http://dx.doi.org/10.1016/j.bandl.2007.11.005.

Paulmann, S., \& Kotz, S. A. (2008b). Early emotional prosody perception based on different speaker voices. Neuroreport, 19(2), 209-213. http://dx.doi.org/10.1097/WNR. Ob013e3282f454db.

Pinheiro, A. P., del Re, E., Mezin, J., Nestor, P. G., Rauber, A., McCarley, R. W., ... Niznikiewicz, M. A. (2013). Sensory-based and higher-order operations contribute to abnormal emotional prosody processing in schizophrenia: An electrophysiological investigation. Psychological Medicine, 43(3), 603-618. http://dx.doi.org/10.1017/ S003329171200133X

Pinheiro, A. P., Barros, C., \& Pedrosa, J. (2016). Salience in a social landscape: Electrophysiological effects of task-irrelevant and infrequent vocal change. Social Cognitive and Affective Neuroscience, 11(1), 127-139. http://dx.doi.org/10.1093/ scan/nsv103.

Pinheiro, A. P., Barros, C., Vasconcelos, M., Obermeier, C., \& Kotz, S. A. (2017). Is laughter a better vocal change detector than a growl? Cortex, 92, 233-248. http://dx. doi.org/10.1016/j.cortex.2017.03.018.

Polich, J. (1997). On the relationship between EEG and P300: Individual differences, aging, and ultradian rhythms. International Journal of Psychophysiology, 26(1-3), 299-317. http://dx.doi.org/10.1016/S0167-8760(97)00772-1.

Polich, J. (2007). Updating P300: An integrative theory of P3a and P3b. Clinical Neurophysiology, 118(10), 2128-2148. http://dx.doi.org/10.1016/j.clinph.2007.04. 019.

Pollak, S. D., \& Tolley-Schell, S. A. (2003). Selective attention to facial emotion in physically abused children. Journal of Abnormal Psychology, 112(3), 323-338. http://dx doi.org/10.1037/0021-843X.112.3.323.

Rajagovindan, R., \& Ding, M. (2011). From prestimulus alpha oscillation to visual-evoked response: An inverted-U function and its attentional modulation. Journal of Cognitive Neuroscience, 23(6), 1379-1394. http://dx.doi.org/10.1162/jocn.2010.21478.

Reed, A. E., \& Carstensen, L. L. (2012). The theory behind the age-related positivity effect. Frontiers in Psychology, 3, 339. http://dx.doi.org/10.3389/fpsyg.2012.00339.

Roach, B. J., \& Mathalon, D. H. (2008). Event-related EEG time-frequency analysis: An overview of measures and an analysis of early gamma band phase locking in schizophrenia. Schizophrenia Bulletin, 34(5), 907-926. http://dx.doi.org/10.1093/ schbul/sbn093.

Rohenkohl, G., \& Nobre, A. C. (2011). Alpha oscillations related to anticipatory attention follow temporal expectations. Journal of Neuroscience, 31(40), 14076-14084. http:// dx.doi.org/10.1523/JNEUROSCI.3387-11.2011.

Sander, K., \& Scheich, H. (2001). Auditory perception of laughing and crying activates human amygdala regardless of attentional state. Cognitive Brain Research, 12(2), 181-198. http://dx.doi.org/10.1016/S0926-6410(01)00045-3.

Sander, D., Grandjean, D., Pourtois, G., Schwartz, S., Seghier, M. L., Scherer, K. R., \& Vuilleumier, P. (2005). Emotion and attention interactions in social cognition: Brain regions involved in processing anger prosody. Neuroimage, 28(4), 848-858. http:// dx.doi.org/10.1016/j.neuroimage.2005.06.023.

Schirmer, A., \& Kotz, S. A. (2006). Beyond the right hemisphere: Brain mechanisms mediating vocal emotional processing. Trends in Cognitive Sciences, 10(1), 24-30. http://dx.doi.org/10.1016/j.tics.2005.11.009.

Schupp, H. T., Junghöfer, M., Weike, A. I., \& Hamm, A. O. (2003). Emotional facilitation of sensory processing in the visual cortex. Psychological Science, 14(1), 7-13. http:// dx.doi.org/10.1111/1467-9280.01411.

Scott, S. K., Lavan, N., Chen, S., \& McGettigan, C. (2014). The social life of laughter. Trends in Cognitive Sciences, 18(12), 618-620. http://dx.doi.org/10.1016/j.tics.2014. 09.002 .

Smith, N. K., Cacioppo, J. T., Larsen, J. T., \& Chartrand, T. L. (2003). May I have your attention, please: Electrocortical responses to positive and negative stimuli. Neuropsychologia, 41(2), 171-183. http://dx.doi.org/10.1016/S0028-3932(02) 00147-1.

Spencer, K. M., Dien, J., \& Donchin, E. (1999). A componential analysis of the ERP elicited by novel events using a dense electrode array. Psychophysiology, 36(3), 409-414. http://dx.doi.org/10.1017/S0048577299981180.

Spencer, K. M., Dien, J., \& Donchin, E. (2001). Spatiotemporal analysis of the late ERP responses to deviant stimuli. Psychophysiology, 38(2), 343-358. http://dx.doi.org/10. $1017 /$ S0048577201000324.

Squires, N. K., Squires, K. C., \& Hillyard, S. A. (1975). Two varieties of long-latency positive waves evoked by unpredictable auditory stimuli in man. Electroencephalography and Clinical Neurophysiology, 38(4), 387-401. http://dx.doi org/10.1016/0013-4694(75)90263-1.

Sutton, S., Braren, M., Zubin, J., \& John, E. R. (1965). Evoked-potential correlates of stimulus uncertainty. Science, 150(3700), 1187-1188. http://dx.doi.org/10.1038/ 020493a0.

Tallon-Baudry, \& Bertrand (1999). Oscillatory gamma activity in humans and its role in object representation. Trends in Cognitive Sciences, 3(4), 151-162. http://dx.doi.org/ 10.1016/S1364-6613(99)01299-1.

Thierry, G., \& Roberts, M. (2007). Event-related potential study of attention capture by affective sounds. Cognitive Neuroscience and Neuropsychology, 18(3), 245-248. http:// dx.doi.org/10.1097/WNR.0b013e328011dc95.

Todd, R. M., Cunningham, W. A., Anderson, A. K., \& Thompson, E. (2012). Affect-biased attention as emotion regulation. Trends in Cognitive Sciences, 16(7), 365-372. http:// dx.doi.org/10.1016/j.tics.2012.06.003.

Weinberg, A., \& Hajcak, G. (2010). Beyond good and evil: The time-course of neural activity elicited by specific picture content. Emotion, 10(6), 767-782. http://dx.doi. org/10.1037/a0020242.

Wildgruber, D., Ackermann, H., Kreifelts, B., \& Ethofer, T. (2006). Cerebral processing of linguistic and emotional prosody: fMRI studies. Progress in Brain Research, 156, 249-268. http://dx.doi.org/10.1016/S0079-6123(06)56013-3.

Yordanova, J., Kolev, V., \& Polich, J. (2001). P300 and alpha event-related desynchronization (ERD). Psychophysiology, 38(1), 143-152. http://dx.doi.org/10.1017/ S0048577201990079. 